\title{
International Conference on Applications of Statistics and Probability in Soil and Structural Engineering ICASP-4: Florence, Italy, 1983
}

The subject matter of ICASP Conferences includes all applications of statistics and probability in civil engineering practice, including design, site supervision, material control and risk assessment.

ICASP-4 will take place from 13 to 17 June 1983 at the School of Engineering of the University of Florence, under the joint sponsorship of the Italian National Group of the International Association for Bridge and Structural Engineering (IABSE-AIPC-IVBH) and of the Italian Geotechnical Association (AGI), the Italian Section of both International Societies for Rock Mechanics (ISRM) and for Soil Mechanics and Foundation Engineering (ISSMFE). The Department of Civil Engineering of the University of Florence will take care of the organization. The Conference language will be English.

Further information may be obtained from Professor Giulano Augusti, Chairman, ICASP-4, Istituto di Ingegneria Civile, Via di S. Marta, 3, I 50139 Firenze, Italy. 